\title{
Functional-anatomical concepts of human premotor cortex: evidence from fMRI and PET studies
}

\author{
Ricarda I. Schubotz* and D. Yves von Cramon \\ Max-Planck-Institute of Cognitive Neuroscience, 04103 Leipzig, Germany
}

\section{Introduction}

The premotor cortex (PM) refers to human Brodmann area 6 (BA6), and often anteriorly adjacent areas BA44 and BA8 are also included. The function traditionally attributed to the PM is the preparation and the organization of movements and actions (Wise, 1985). However, with the introduction of imaging methods, which allow the neural correlates of behavioral functions to be measured online, premotor activations have frequently found in nonmotor "cognitive" domains. As these findings were difficult to interpret in light of the classical motor view, they were typically taken to reflect some kind of latent motor processes. As such, they were experimental artifacts of either nonsuppressible or deliberately chosen behavioral strategies, like verbalizing or tapping, or simply movement noise.

However, nowadays the exploration of cognitive function of the human premotor cortex has become an independent field of research, supported and also inspired by results from research in the monkey. Hence, currently a diversity of concepts of PM functions coexist, referring partly to the classical motor account, partly to the scope of nonmotor functions.

With particular interest in the nonmotor domain, the present paper aims to outline current concepts of human PM functions as have emerged from imaging results. Concepts apply to functional-anatomical dissociations of right vs left, medial vs lateral, rostral vs caudal, and dorsal vs ventral PM. In view of widely missing macroanatomical borders between PM subsections, these labels can serve only as a gross orientation. Moreover, the investigation of cortical architecture in living humans on the microanatomical level using specific MR protocols is still restricted to a resolution of about $500 \mu \mathrm{m}$ (Damasio, 1991). As we lack direct evi-

* Corresponding author. Fax: +49-341-9940-135/221.

E-mail address: schubotz@cns.mpg.de (R.I. Schubotz). dence from individual cytoarchitectonic data in conjunction with functional results, any potential correspondences between subsections of the human and the monkey PM are based on functional rather than on anatomical homologies (e.g., Rizzolatti et al., 2002).

The scope of the present paper is limited. It focuses on imaging studies (in contrast to other methods in humans and in contrast to monkey studies), on the lateral (in contrast to medial) PM, and on functional trends along the dorsalventral axis. Concepts are illustrated by some representative findings only.

\section{Right versus left PM}

Two concepts of hemispheric differences in PM exist. According to one, the right PM is more frequently engaged by spatial tasks, whereas the left PM shows a preference for nonspatial tasks. For instance, color-cued responses activate the left PMv, spatial cued responses the right PMv (Hazeltine, 1997). A right PM dominance was reported for spatial working memory (Haxby, 1994; Jonides, 1993), spatial exploration (Gitelman, 1996), spatial body-centered judgment (Galati et al., 2001), and spatial attention (Gitelman, 1999; Kim et al., 1999). These findings may be seen in light of the more general view that the right hemisphere is engaged in global compared to local information processing on the perceptual level (Hellige, 1996). A different view of hemispheric specialization refers to effects of manual sequence learning when pure motor effects are balanced and controlled. Here, the left PM is taken to be dominantly involved during the acquisition of new motor sequences, even if performed with the nondominant hand, whereas the right PM is rather involved in advanced learning stages and sequence storage (Grafton et al., 2002; Lafleur et al., 2002; Mueller et al., 2002; Sakai et al., 2002; Schubotz et al., 2000; Toni et al., 2001). As far as complex sequences 
require more storage load than simple sequences, the storage hypothesis is supported by the finding that especially the right PM co-varies positively with the complexity (mostly the length) of sequences (Sadato, 1996). The same effect has been found in purely perceptual sequence learning (Schubotz and von Cramon, 2002a,c). Again, this concept may be seen as corresponding to more general concepts of hemispheric asymmetry that stress the right brain's role in sustained attention (Sarter et al., 2001) and enhanced interhemispheric exchange under high task demands (Banich, 1998).

\section{Lateral versus medial PM}

As functional differences between lateral and medial PM have been addressed in a recent review on imaging studies, we confine this paragraph to a spotlight on this issue (Picard and Strick, 2001). Several imaging studies have investigated externally versus internally paced or cued movement in order to replicate a functional dissociation between lateral and medial PM in the monkey (Goldberg, 1985; Passingham, 1993). However, findings appear much more diverse in humans than in animals. Cunnington and colleagues (2002) report no lateral premotor activation for either internally or externally triggered movements, but medial premotor cortex for both. In contrast, Larsson et al. (1996) found lateral PM in both conditions, but medial PM in internally paced movements only. Several studies report both lateral and medial PM in both externally and internally cued conditions, though with different dominances (Weeks et al., 2001; Wessel et al., 1997; Crosson et al., 2001). Weeks and colleagues report both target areas to be enhanced in the internal manipulation. Wessel et al. find lateral dominance for externally-paced conditions and medial dominance for internally-paced conditions, as expected from monkey data. However, the authors concede that enhanced lateral PM could be caused by more movements in the externally cued condition. Finally, Crosson and co-workers also confirm SMA enhanced in free and PM in paced silent word generation. Together, findings point to a principal trend for medial PM dominance in internally guided and lateral PM in externally guided movement. As concepts of the right-left dissociation, this medial-lateral distinction can be seen in a broader functional context. Thus, the medial PM's impact on internally guided as opposed to externally triggered movement supports the role of the frontomedian wall in action initiation and motivation (Seitz et al., 2000).

\section{Rostral versus caudal PM}

Two main functional and anatomical characteristics apply to rostral-caudal differences in the monkey PM. First, PM neurons with sensory properties are more frequently found in the rostral PM, and those with motor properties more frequently in the caudal (Johnson et al., 1996; Shen and Alexander, 1997; Wise, 1997). Second, direct projections exist between rostral PM and prefrontal areas on the one hand and between caudal PM and M1 respectively the spinal cord on the other (Marconi et al., 2001; Dum and Strick, 1991; Ghosh and Gattera, 1995). Both properties indicate that rostral PM fields may be rather seen as functionally belonging to the prefrontal cortex, whereas caudal $\mathrm{PM}$ is rather conceived of as a true motor area that is primarily involved in movement execution.

In humans, as in monkeys, a functional rostrocaudal dissociation has been described predominantly for the medial PM, separating it into the rostral pre-SMA and the caudal SMA proper, but the same distinction was recently also proposed to hold for lateral PM, especially PMd (prePMd vs PMd proper; Picard and Strick, 2001). Together, three functional trends are suggested to follow the considered rostral-caudal anatomical gradient: one going from complex to simple execution, the second from intention to execution of action, and the third from early to late (sensori)motor learning stages. Considering the latter two dissociations, it appears that the rostral PM is involved earlier than the caudal PM both in the narrow time scale (from intention to execution within a trial, e.g., Boussaoud, 2001; Simon, 2002) and in a wider time scale (from early to late learning stages within an experimental session, e.g., Inoue et al., 2000; Iacoboni et al., 1998). Note that all considered studies report rostral-caudal differences within PMd, and all employ spatial tasks. In the light of the spatial processing functions of PMd as opposed to PMv (see Right versus left $\mathrm{PM}$ ), it remains an open question whether the same rostral-caudal differences could be also found in PMv.

\section{Dorsal versus ventral PM}

Monkey PM is subdivided into PMd (F2, F7) and PMv (F4, F5) at the level of the spur of the arcuate sulcus (arcuate spur), two fields that differ with respect to their corticocortical connections (Ghosh and Gattera, 1995) and their cells' functional properties. It has been proposed that human PMd is located superior and PMv inferior to $z=51$ of Talairach space (Rizzolatti et al., 2002, modified in Fig. 1). If this view is adopted, then first, human PMv is proportionally much larger than human PMd, and second, the majority of the PM activations reported in human imaging studies actually refer to PMv. In view of the functional characteristics of the monkey PMd, which will be outlined below, this may be not surprising. Note that in most imaging studies, however, the labels "PMv" and "PMd" are used to denote PM activations inferior and superior to the (virtual continuation of the) inferior frontal sulcus, dividing PM into two fields of roughly the same size. Hence, activations typically attributed to PMd may actually lie within the dorsal rim of PMv.

Dorsal-ventral differences in the monkey PM are strongly characterized by a somatotopical representation 
that roughly parallels that in M1. The caudal PMd represents hindlimbs superior and medial to the forelimbs, PMv contains both forelimb and orofacial representations that show a larger overlap than representations in PMd and than corresponding representations in MI (Godschalk et al., 1995; Fogassi et al., 1999). Electrical stimulation suggests that PM contains a representation of complex postures, with a dorsal-to-ventral gradient for leg and foot, arm with hand, and finally face and mouth (Graziano et al., 2002). Evidence has accumulated that one or several body maps also exist in the human PM. This becomes evident in movement-related behaviors, particularly under specific requirements of (skillful) control, (interlimb) coordination, and (sensorimotor) integration or specific cognitive demands. This pattern emerges also across paradigms that require only the imagery or the observation of motion or action, i.e., in the absence of overt motor execution (e.g., Buccino et al., 2001). In these paradigms, PM correlates can be taken to reflect "covert (stages of) action" (Jeannerod, 2001), which as such would be expected to follow the same limb-dependent representation as overt action. Fig. 2 shows the sagittal and the coronal distributions of activation coordinates from corresponding imaging studies.

However, only across a larger set of studies does it become obvious that in perceptual-attentional tasks in which neither the execution nor the imagination of action or movement is called for, premotor activations still appear to follow a somatotopy. This is most evident from covert spatial attention, which engages PMd, and object-directed attention, which engages PMv. The latter effect is particularly induced by tools, i.e., objects which implicate a specific, highly trained action, and therefore has been discussed as reflecting representations of action knowledge or object usage. As shown in Fig. 2, spatial attention activates PM areas which are also activated by arm movements and saccades, whereas object attention engages PM fields typically engaged in hand and finger movements. Furthermore, bodyreferenced PM activation is reported for imagery and observation of nonbiological motion. Thus, dorsal PMv and/or PMd is typically reported for mental rotation, and inferiormost PMv (BA6/44) has been observed for the imagery of nonbiological dynamic auditory stimuli (Fig. 2). Activations may reflect the imagination of spatial manipulation using hands, arms, and eyes or covert vocal coproduction (but see also Parsons, 2001). Together, findings suggest that PM somehow represents not only imagined movement of one's own body but also (current or expected) sensory features of the environment in reference to one's own body.

The core suggestion of this account is not new in monkey research, though a specifically dynamic or anticipatory aspect has not been relevant in concerned studies. Monkey PM neurons serve a variety of functions involving both

Fig. 1. The monkey PM (A, C) is subdivided into six fields as introduced by Matelli and co-workers (1985): caudal medial (F3), rostral medial (F6), caudal dorsal (F2), rostral dorsal (F7), caudal ventral (F4), and rostral ventral (F5). The primary motor cortex is labeled F1. Based on functional evidence, it has been proposed that the human homologues (B, D) of F5 and F7 are located anterior and F4 and F2 posterior to the inferior and the superior precentral sulcus, respectively. The border between ventral and dorsal PM, i.e., between F4 and F2, was suggested to correspond to $z=51$ in Talairach space (Talairach and Tournoux, 1988) in the human brain. Suggested homologies are based largely on investigations of movement, but also on more recent evidence from PM correlates in perception of objects and actions (A, C and D modified from Rizzolatti et al., 1998 and 2002).

Fig. 2. Somatotopy of premotor activations in motor and in cognitive tasks: Talairach coordinates of premotor activation maxima reported in fMRI and PET studies. The sagittal ( $y$ axis $/ z$ axis) distribution, neglecting the $x$ axis, is displayed in the first (upper) row, the second row shows the coronal ( $x$ axis $z$ axis) distribution neglecting the $y$ axis. Corresponding upper sagittal and lower coronal graphs show (from left to right) activation maxima as found during execution, imagery, observation of action or biological motion, the imagery and observation of nonbiological motion and objects, and during nonmotor serial prediction tasks. Color codes refer to different effectors in motor tasks and to attended stimulus properties in cognitive tasks. All activations are summarized in a common schema in the lowest panel on the left side and are also plotted on brain sections on the right side. Activations were taken from the following studies: Execution of action/biological motion, Anderson et al., 1994; Binkofski 1999; Corfield et al., 1999; De Jong, 1999; Ehrsson et al., 2000, 2001, 2002; Fox et al., 2001; Hamzei et al., 2002; Haslinger et al., 2002; Kawashima, 1996, 1998; Kertzman et al., 1997; Kuhtz-Buschbeck et al., 2001; Lafleur et al., 2002; O'Driscoll et al., 1995; Sadato et al., 1996 Imagery of action/biological motion, Bonda et al., 1995; Decety, 1994; Gerardin et al., 2000; Johnson et al., 2002; Lafleur et al., 2002; Parsons et al., 1995; Shergill et al., 2001; Thobois et al., 2000; Vingerhoets et al., 2002 Observation of action/biological motion, Buccino, 2001; Campbell et al., 2001; Decety, 1997; Iacoboni et al., 1999; MacSweeney, 2000; Manthey et al., 2003; Von Cramon and Schubotz, 2003 Imagery and observation of nonbiological motion and objects, Chaminade et al., 2001; Corbetta et al., 1993; Gerlach et al., 2002; Grabowski et al., 1998; Grafton et al., 1997; Griffiths, 2000a,b; Halpern and Zatorre, 1999; Lamm et al., 2001; Martin et al., 1995, 1996; Nobre et al., 2000; Ramnani et al., 2000; Vingerhoets et al., 2002 Serial prediction, Schubotz et al., 2000; Schubotz and von Cramon, 2001a,b, 2002a,b,c; Schubotz et al., 2003.

Fig. 3. Example for the serial prediction task paradigm (from Schubotz and von Cramon, 2002b, reproduced by permission of the publisher). A sequence of stimuli is presented either in the visual or in the auditory domain. In most studies, the stimulus material is abstract in order to avoid coactivations by semantic or episodic memories. A typical trial length is $6 \mathrm{~s}$, with an intertrial interval of 6 to $8 \mathrm{~s}$. The stimulus sequence is temporally structured, consisting in repetitive, monotone, or combined repetitive and monotone sequences. Complexity and thereby task demands can be varied on different levels, for instance by sequential structure, by sequence length, or by discriminative perceptual demands. Sequential structure is provided only within the attended stimulus property (e.g., the pitch of a tone sequence), whereas other stimulus properties are presented in randomized order (e.g., the spatial sources of tones or their temporal duration). In half of all trials, sequences contain a sequential deviant within the last sequence elements, that is, the order of two elements is flipped. Subjects are asked to attend to a specific stimulus property, for instance to color, orientation, or pitch, while ignoring other features, and to find out how the sequence will evolve further on. At the end of a trial, subjects have to indicate in a forced-choice mode whether the sequential order of the to-be-attended stimulus property was correct until the end of presentation or whether it was violated. Tasks which provide the same amount of physical information without requiring the identification and prediction of a sequential structure serve as control conditions. This can be for instance a target detection task or a serial match-to-sample task (as given). In a serial match-to-sample, the first stimulus in a trial (probe) has to be remembered and compared with each of the following stimuli. Subjects are requested to indicate if the same stimulus reappears (target) or not. 


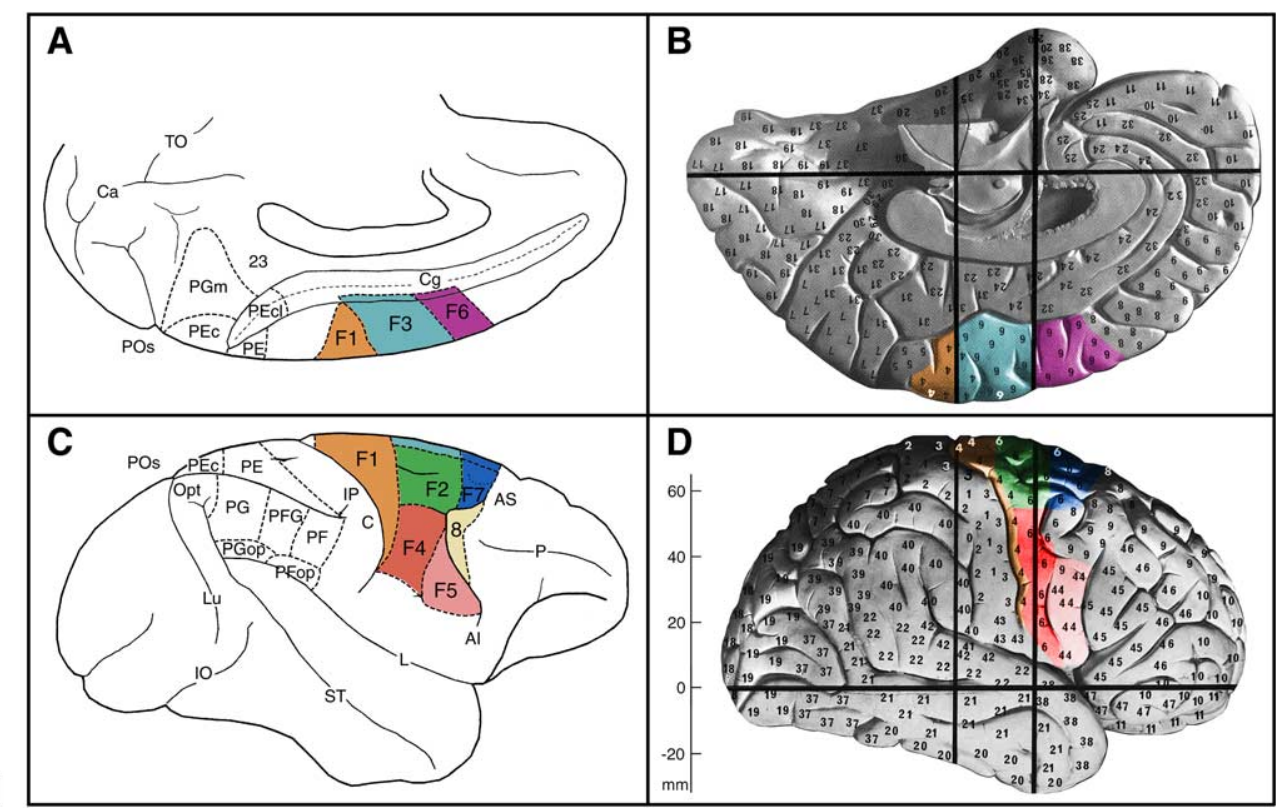

motor tasks

cognitive tasks

$\square$ foot $\square$ eyes $\square$ hand/arm $\square$ hand $\square$ finger $\square$ mouth

$\frac{\square \text { spatial } \square \text { object } \square \text { rhythm/pitch }}{\text { imagery + observation serial prediction }}$
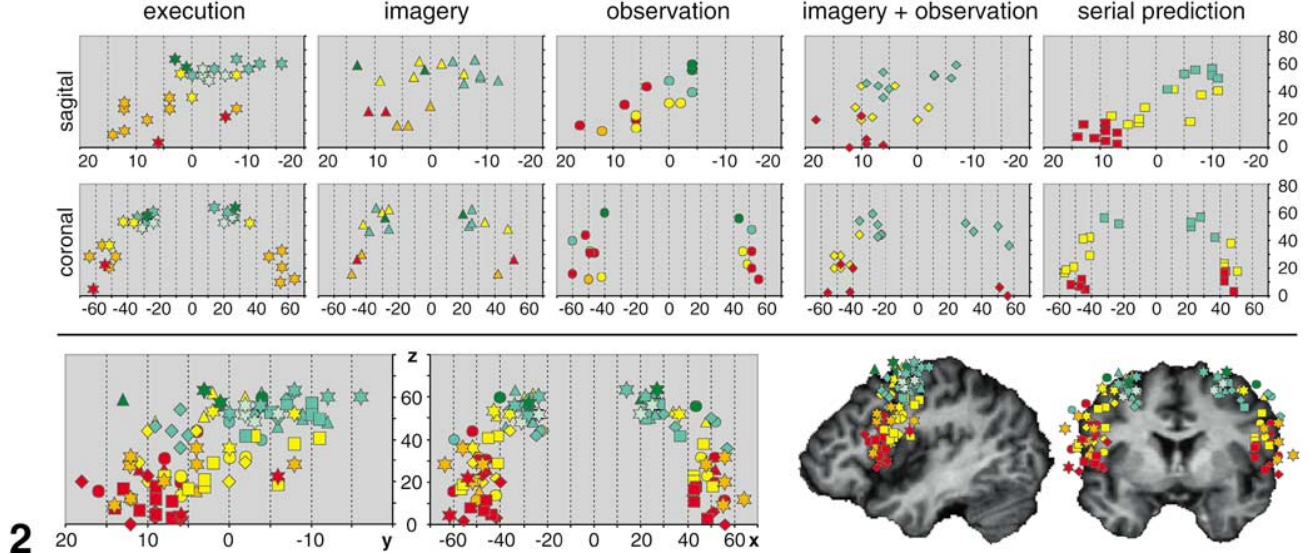

2

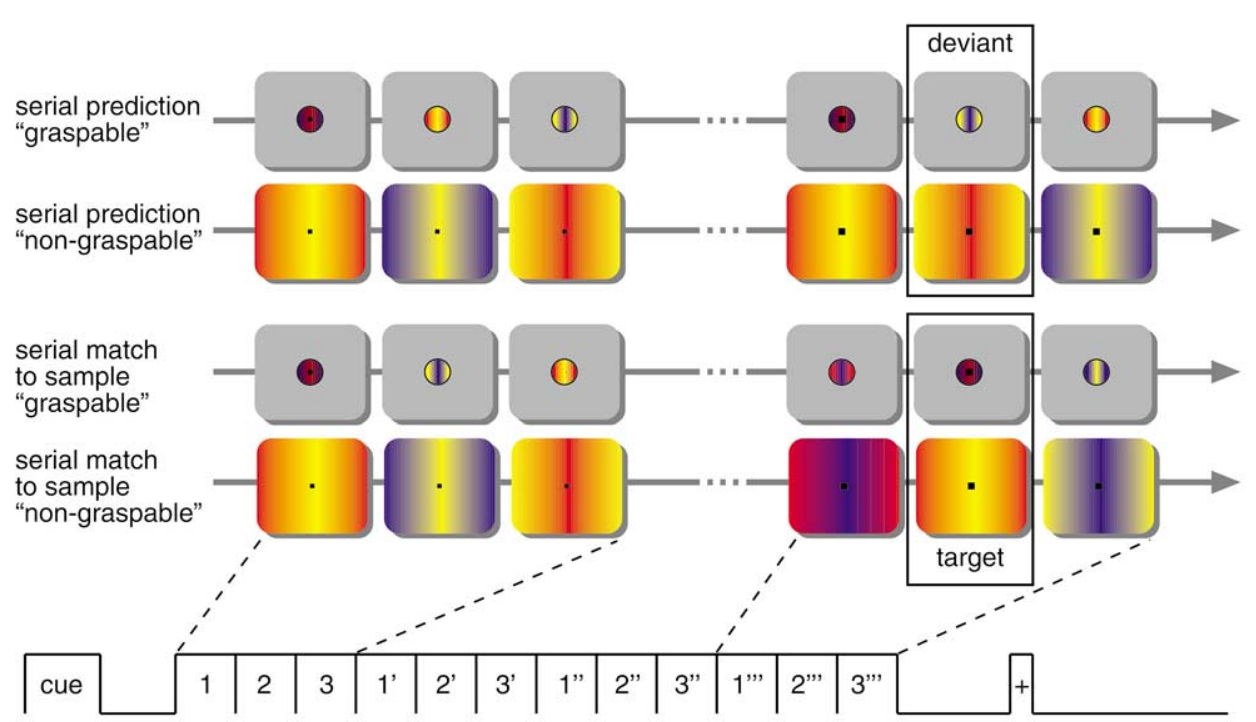

3

time

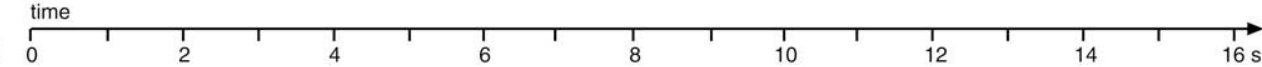



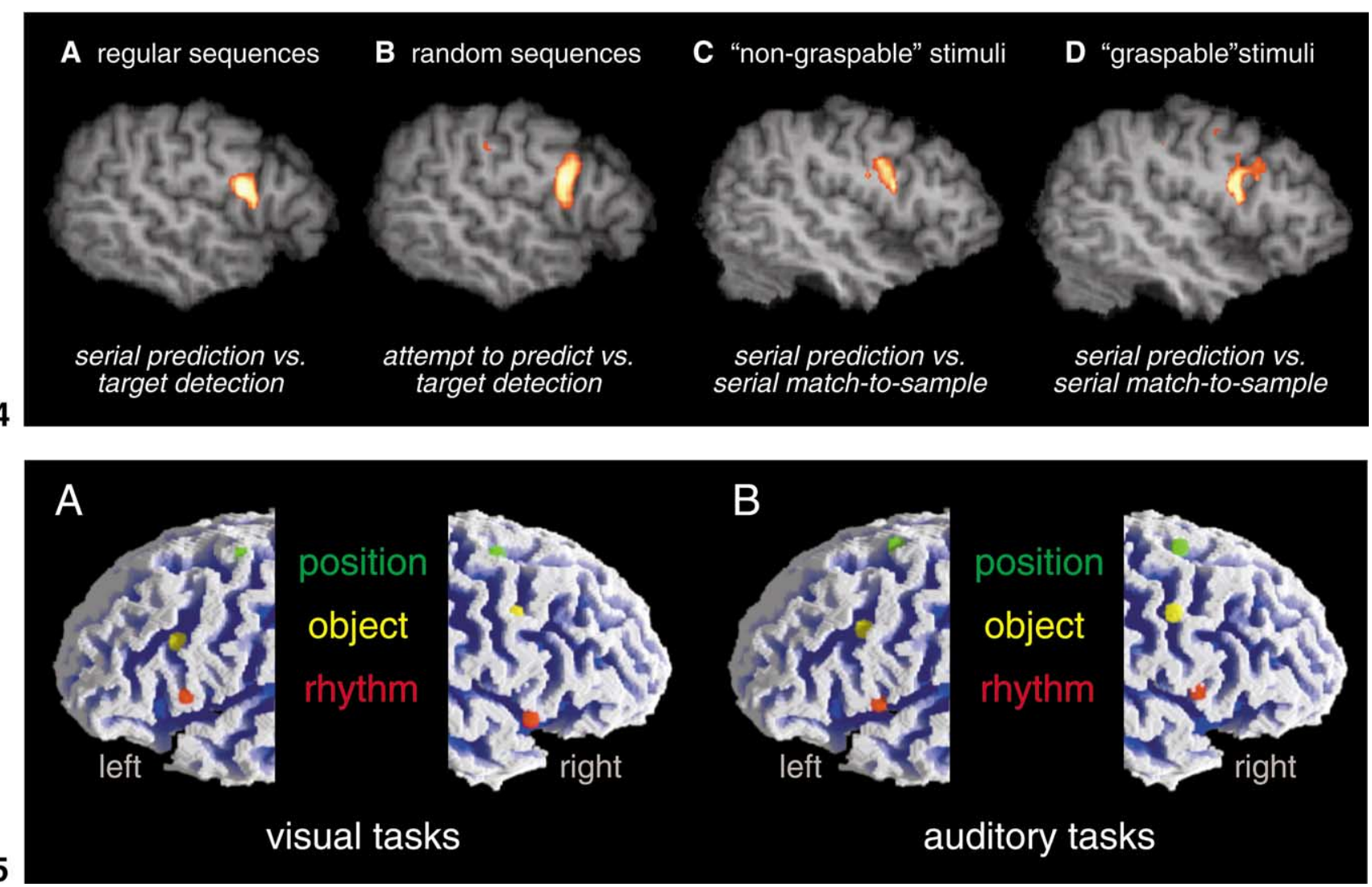

Fig. 4. PMv activation (right hemisphere) from two visual serial prediction task (SPT) paradigms (A and B, Schubotz and von Cramon, 2002a; C and D, Schubotz and von Cramon, 2002b). (A) Standard contrast between SPT performed on regular sequences and a target detection task performed on random sequences. (B) Same SPT task as in A, but performed on random sequences. (C and D) SPT tasks performed on "nongraspable" and "graspable" abstract stimuli, respectively, each in contrast to equally difficult serial match-to-sample tasks (see also Fig. 2). Strikingly similar activations indicate that PM is reliably activated by prospective attention to sensory events and that this activation cannot be explained by some kind of latent (grasping) action toward stimuli.

Fig. 5. Influence of the attended sensory property on premotor activation (A, Schubotz and von Cramon, 2001; B, Schubotz et al., 2003). No matter whether performed on visual (A) or auditory (B) stimuli, the prediction of spatial, object-related, and temporal sequences engages three different lateral PM areas. As argued in the corresponding papers, we suggest that these three activation foci reflect a body-referenced representation of attended events ("habitual pragmatic body map"). Hence, pragmatic features of spatial events are reflected within PM areas for reaching and saccades, those of objects within PM areas for grasping and manipulation, and those of rhythm (or pitch) in PM areas related to vocal production.

sensory and motor representations. In registration to the PM body map, tactile receptive fields are arranged, often also anchored to visual receptive fields (review see Graziano, 2001) and, less frequently, to both visual and auditory ones (Graziano and Gandhi, 2000). Accordingly, for example, F4 not only organizes head and arm movement, but also codes space. It is still a matter of debate if this is a coding of motor space or a coding of perceptual (visual) space in somatocentered coordinates. In either case, however, environmental features are coded as a reference frame for a particular set of effectors (Fogassi et al., 1996; Gentilucci et al., 1988; Rizzolatti et al., 1988). Therefore it has been proposed that PM represents "motor ideas" that may provide the basis for space representation, understanding actions, and object categorization (Fadiga et al., 2000), that is, in other words, cognitive functions.

As a working hypothesis we therefore have suggested that neurons with sensory receptive fields for mouth, hand, and arm may account for the "pragmatic body map" that emerges from tasks like mental rotation, object categorization, and music imagery. These tasks overlap in that they require the imagery of a dynamic scene or signal, but differ with respect to the environmental properties that are mentally manipulated or simulated in this way. For instance, the prediction of writing-like trajectories activates dorsalmost $\mathrm{PMv}$, that of pointing-like trajectories the middle PMv (Chaminade et al., 2001), and learning auditory event prediction corresponds to an increase in the inferiormost PMv (Ramnani et al., 2000). Each of these tasks corresponds to sensory events that are usually caused by or engaged in movement of the arm and eyes (spatial locations and orientations), the hand and fingers, sometimes the mouth (object properties), or the vocal effectors (auditory and rhythmic features). The possible existence of such a pragmatic body map and the hypothesis that PM might serve as an internal forward model of environmental dynamics has been sys- 
tematically investigated in a series of fMRI studies, as will be outlined in the following section.

Before turning to this issue, however, a final concept of ventral-dorsal dissociation of PM has to be considered: PMd is considered to code "supramodal" sequences or action plans, whereas in contrast, PMv is taken to code the "surface properties" of those sequences. Thus, a reliable effect across several imaging studies is that if only sequential complexity is increased, while leaving other features constant, PMd shows enhanced activity (Haslinger et al., 2002; Harrington, 2000; Boecker et al., 2002). However, a possible confound arises from the usage of response sequences that are arranged horizontally, as such response arrangements allow for sequences to be learned as spatial sequences, a problem addressed by authors themselves. PMd may thus become engaged due to its function in space coding. Moreover, as Hanakawa and colleagues (2002) have pointed out, a general interpretational problem arises from the fact that manual sequences can be coded by the assignment of numbers, for which visuospatial networks-including PMd-would also be expected (Simon, 1999). Authors discuss that PMd computes spatial information to manipulate mental representations as well as physical objects rather than coding abstract sequences. Hence, even if sequential complexity is manipulated in a finger-opponent task (as for instance in Sadato et al., 1996), it cannot be ruled out that PMd covaries with spatial rather than with "abstract" sequence-specific complexity. Note also that Mushiake and co-workers (1991) are often cited in support of a sequencespecificity of PMd as opposed to PMv. However, though sometimes cited falsely, these authors report a set- and sequence-specific preference not in PMd (as opposed to PMv) but in SMA (as opposed to PM).

The spatial confound problem persists even in paradigms on abstract sequential (or action) planning, which typically use computer versions of the classical Tower of London (Hanoi). PMd activation reported in these studies may indeed reflect abstract planning, but those planning demands covary with spatial task demands that may require "imagined movement of the mind's eye and finger" (Baker et al., 1996). Of course this does not rule out but only complicates the interpretation of existing imaging results in favor of amodal versus modal coding in PMd versus PMv, respectively. This problem can be resolved by investigating increasing complexity in nonmotor sequential tasks that do not allow for numerical coding. In fact, results from those can be reconciled with (but do not necessarily imply) the supramodal/modal dissociation (Hanakawa et al., 2002; Schubotz and von Cramon, 2002a,c).

Nonmotor functions of PM can best be investigated if behavioral responses are abandoned as far as possible. In order to investigate which factors modulate dorsal-ventral differences in PM activation under nonmotor requirements, we developed the serial prediction task (SPT) paradigm (Schubotz, 1999). As a perceptual counterpart to the serial reaction task (Nissen and Bullemer, 1987), it requires se- quential processing, but on an explicit and purely perceptual level (Fig. 3, see legend for details of the task). Across a series of fMRI studies using the SPT paradigm, a number of effects have proved to be robust. These will be sketched in the remaining paragraph.

\section{(a) PM is engaged in prospective attention to sensory events}

Activation of PM was found to depend solely on the subject's attempt to extract and predict a sequential pattern from the stimulus train and not on the presence or the detectability of a sequential pattern. Hence, PM is activated whenever subjects are instructed to predict serial events compared to a target detection task using the same physical input, and this applies even if the presented sequences are in fact randomized (Figs. 4A and 4B) (Schubotz and von Cramon, 2002a). Note that this effect does not result from different task demands in the compared conditions. For instance, PM activation is found when serial prediction is contrasted with an equally difficult serial match-to-sample task (Figs. 4C and 4D) (Schubotz and von Cramon, 2002b). The relevance of a predictive task for PM engagement may also be reflected by the absence of PM activation in a motion observation task that does not require prediction (Perani, 2001). In this respect, our findings fit well with a recent study that investigated the influence of task on PM activation (Chaminade et al., 2002). Authors observed PMv response to manual action observation only if the goal or outcome of said action was to be subsequently imitated, pointing to a final state coding within PMv (see also Umilta et al., 2001). Correspondingly, the attempt to extract the expected final state from either an observed action or an abstract visual sequence was found to engage the same $\mathrm{PMv}$ areas within both hemispheres (Von Cramon and Schubotz, 2003). We therefore propose PM to maintain a short-term representation of structured dynamics based on which either sensory prediction or action planning can be performed.

\section{(b) PM correlates of prospective attention follow a pragmatic body map}

PM activations in serial prediction were found to be distributed according to the to-be-predicted stimulus features, and the overall pattern of these activations strongly suggests that they follow a "sensory," "virtual," or "pragmatic" body map (Schubotz and von Cramon, 2001a; Schubotz et al., 2003). Within the same experimental setting, we found rhythm prediction to engage the inferiormost PMv (face/mouth area), object prediction the (left) middle $\mathrm{PMv}$ (hand area), and spatial prediction the dorsalmost PMv and/or PMd (arm area) (Fig. 5). This distribution of activation was observed both in visual and in auditory studies. We take these results to confirm that, as proposed in monkey, PM participates in the representation of the pragmatic fea- 
tures, i.e., the potential motor significance, of attended sensory events (Fadiga, 2000). It is important to consider that the somatotopical distribution of PM activation in nonmotor tasks does not allow a decision to be made between two alternatives: whether premotor activation reflects "motor" correlates of sensory events or rather truly "sensory" correlates. It is of course possible that premotor neurons that respond to sensory events do not code potential arm, hand, and mouth movements, but rather spatial, object, and rhythmic or pitch features. Moreover, a "supramodal" coding is also conceivable in principle. The concept of a pragmatic body map is not intended to exclude one of these alternatives.

\section{(c) PM is notably flexible with respect to sensory representations}

PM activation was found to depend significantly on the attended stimulus property, but to be independent of the employed stimulus material. Hence, PM is activated for instance not only by natural objects, but also by nonnatural objects (figures) or nonnatural noises. We have found significant PM activations for any type of abstract visual and auditory stimulus material. In a certain sense, however, one could argue that small geometrical objects are reminiscent of graspable objects. Therefore, we systematically investigated the influences of stimulus features in two fMRI studies, which showed that PM did not covary with the size (or virtual "graspability") of presented object stimuli (Schubotz and von Cramon, 2002b). Examples for the stimulus material and results of the second experiment in this publication are shown in Figs. 2 and $4 \mathrm{C}$ and $4 \mathrm{D}$, respectively. In addition, findings also indicate that PM activation cannot be attributed to a latent action like grasping, but rather reflects a body-referenced but abstract representation of attended sensory properties. Further evidence for this high level of abstraction comes from a study that compared serial prediction performed either on videotaped manual action or on abstract geometrical object sequences (Von Cramon and Schubotz, 2003) and a study that employed machine-like sounds that were not producible by human voice (Schubotz et al., 2003). We suggest that environmental features do not have to remind us of specific actions or movements to induce PM activation on a more or less conscious level. Rather, features are represented in a highly fragmented format that allows for instant recombination and very flexible coding of any currently attended environment.

\section{(d) PM fields show modality preference, but no specialization}

In addition to and independent of property-dependent PM modulations described so far, sensory modality of attended events appeared to have an influence on PM activation too. Particularly, inferior PMv and superior PMv are preferentially activated by auditory and visual stimuli, respectively. Moreover, increasing sequential complexity in an auditory and in a visual prediction task was found to covary positively with the BOLD signal in these two PMv subregions. At the highest level of complexity, PMd (or the dorsal rim of PMv) was activated independent of modality (Schubotz and von Cramon, 2002c Fig. 6). Note, however, that in this study, the influence of auditory pitch was compared with visual size sequences so that both effects of property and effects of modality were concurrently manipulated. We therefore addressed the issue of modality specificity in an auditory and a visual study, each employing serial prediction conditions of temporal, object-related, and spatial events (Schubotz and von Cramon, 2001a; Schubotz et al., 2003). In addition to the described property-dependent PM modulations, visual and auditory serial prediction generally elicited activation within the superior PMv and the inferior PMv, respectively (Fig. 6). Currently it cannot be excluded that superior PMv activation emerges because the processing of object properties is not suppressed in visual sequences, whereas inferior PMv is activated by unsuppressed rhythmic processing in auditory sequences.

\section{(e) PM reflects a task-relevant process in serial prediction}

In addition to $\mathrm{PM}$, its parietal projection sites were coactivated in serial prediction tasks in most studies. As we know from research in the monkey, premotor and parietal areas form multiple parallel loops for sensorimotor transformation (Rizzolatti et al., 1998). While functional-anatomical properties of the PM have been focused on in the present paper, of course parietal projection sites substantially contribute to considered functions. A crucial question is therefore whether premotor or parietal areas alone may account for performance in serial prediction. Using fMRI, it is impossible to test an area's task relevance: It is principally possible that a significant BOLD response reflects a (redundant) behavioral strategy, and it is also possible that activation within actually task-relevant areas fails to reach statistical threshold. In light of these methodological limitations, we conducted a patient study, testing the hypothesis that PM lesions do not affect performance in a serial prediction task. As a result, this hypothesis could be rejected. Following our expectations, compared to parietal and prefrontal patients, premotor patients were most significantly impaired in all three tested types of visual serial prediction (Fig. 7; Schubotz et al., submitted).

Considering the functional properties of dorsal and ventral PM that have been outlined above, the findings from SPT paradigms indicate a body-referenced representation of sensory events in human PM. Thus, PMd is engaged in movements of foot and arm and in spatial information processing, whereas PMv is engaged in movements of fingers, mouth, and vocal tract and in object information processing. Within this latter compartment, the inferiormost 

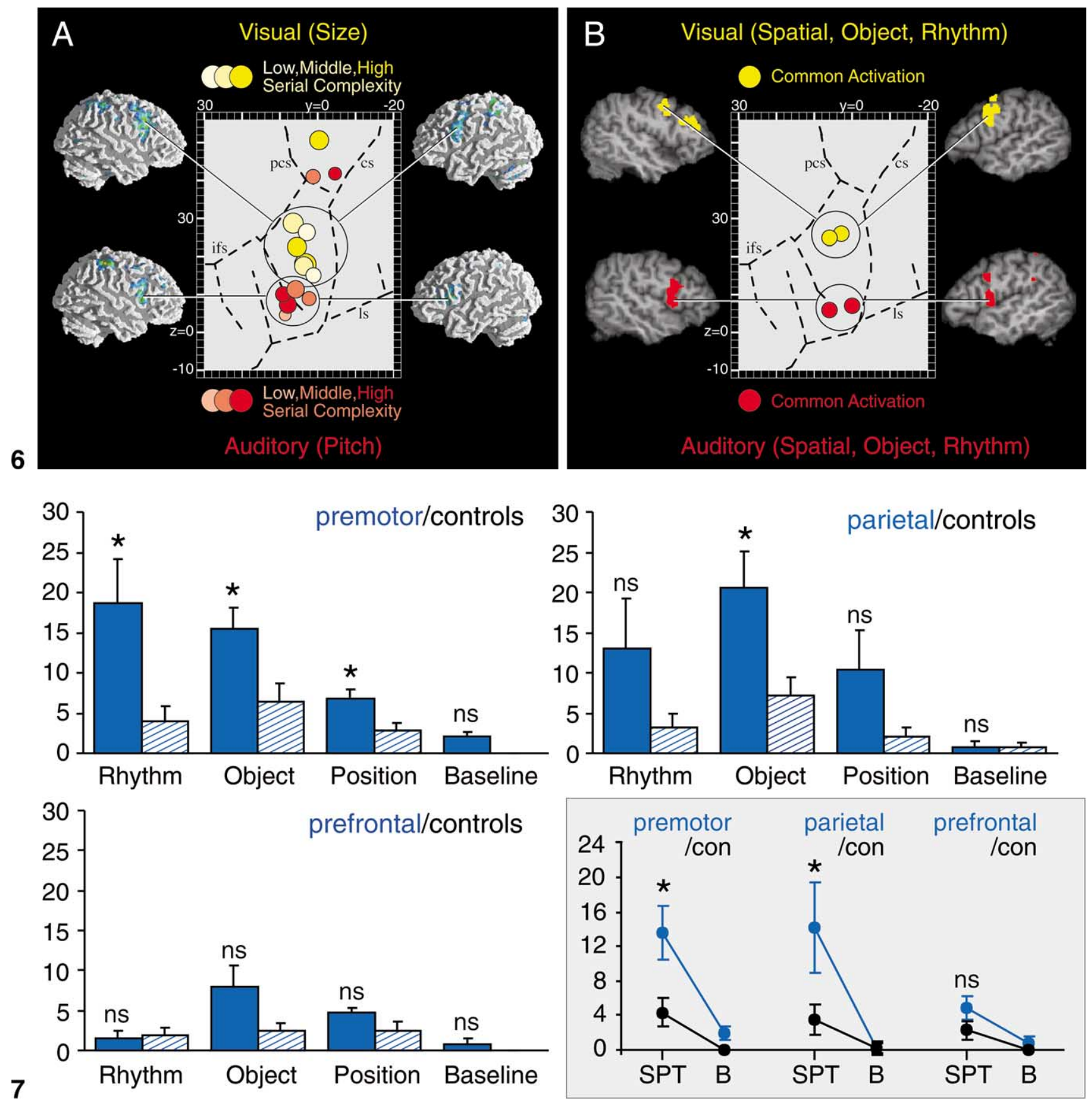

Fig. 6. Influence of the sensory input modality on premotor activation (A, Schubotz and von Cramon, 2001; Schubotz et al., 2003; B, Schubotz and von Cramon, 2002c). Between-study and within-study comparisons show that, in addition to effects of the attended stimulus property (see Fig. 5), visual stimuli generally engage superior PMv, whereas auditory events rather engage inferior PMv. Anatomical abbreviations: pcs, precentral sulcus (inferior and superior); ifs, inferior frontal sulcus; 1s, lateral sulcus; cs, central sulcus.

Fig. 7. Behavioral performance in an SPT paradigm investigated in patients with lateral premotor, parietal, and prefrontal lesions (Schubotz et al., submitted). Findings indicate that both premotor and parietal (but not prefrontal) lesions lead to significant impairments in the SPT. This finding renders it unlikely that the premotor activations during SPT as found in fMRI reflect task-irrelevant co-activations.

portion of PMv (BA6/44) is engaged in the processing of temporal (rhythm) information and pitch, what has, as far as we know, not yet been investigated in the monkey. The present account integrates both effector-specific modulations and information-specific modulations of PM. It supports the view that spatial attention is a consequence of an activation of brain areas which are also involved in the transformation of spatial information into action (the Premotor Theory of Attention, Rizzolatti et al., 1987). Likewise, however, object attention and attention related to speech-related properties like pitch (frequency) and rhythm may be a consequence of an activation of brain areas (in- 
cluding PM) which are also involved in the transformation of object (pitch, rhythm) information into action.

As reported effects become especially evident when the prediction of environmental dynamics is required, rather than merely attending to environmental static features, it is suggested that the premotor cortex is an action-related forward model of what the organism expects to experience in short term. To this end, multiple premotor-parietal loops, each linking both heteromodal and unimodal representations, may be exploited by the pre-SMA and prefrontal areas for perception, action, and imageries; visual, auditory, or tactile predictions or imageries might be generated by efferent signals to and feedbacks from the corresponding unimodal association cortices, with current internal and external requirements determining which feedback becomes causally effective. Two behavioral implementations of PM as such a forward model can be considered. First, being prepared for the near future enables us to react quickly and appropriately. Following the medial-lateral dichotomy outlined above, activation within lateral PM may correspond to the effector that is habitually guided by the attended sensory signal. Alternatively, however, activation within lateral PM may correspond to the effector that habitually causes the attended sensory signal. This account of PM goes beyond the classic term of a passive action-perception adaptation module. It considers PM as that part of a network that represents upcoming events, no matter if these are caused by an external source or by the subject/animal itself. This account may be conceived of as neurofunctional counterpart to a psychological model that considers actions to be planned in terms of intended sensory effects, the Theory of Event Coding (Hommel et al., 2001).

\section{Conclusion}

Together, the findings point to a dual PM function, one related to motor output, the other to attentional and receptive functions, both referenced to a body map. We especially propose that dorsal-ventral differences in attentional nonmotor tasks that engage PM can be explained by their representation according to a "habitual pragmatic body map." In contrast to the historic view, but in accordance with recent findings in the monkey, imaging data indicate that PM may be involved in a variety of behaviors, with motor execution being merely the tip of the iceberg. In light of research in the monkey, imaging studies can especially help to further elucidate how cognitive abilities may have evolved from motor functions and structures.

\section{References}

Anderson, T.J., Jenkins, I.H., Brooks, D.J., Hawken, M.B., Frackowiak, R.S., Kennard, C., 1994. Cortical control of saccades and fixation in man: a PET study. Brain 117, 1073-1084.
Baker, S.C., Rogers, R.D., Owen, A.M., Frith, C.D., Dolan, R.J., Frackowiak, R.S., Robbins, T.W., 1996. Neural systems engaged by planning: a PET study of the Tower of London task. Neuropsychologia 34, 515-526.

Banich, M.T., 1998. The missing link: the role of interhemispheric interaction in attentional processing. Brain Cognit. 36, 128-157.

Binkofski, F., Buccino, G., Stephan, K.M., Rizzolatti, G., Seitz, R.J., Freund, H.J., 1999. A parieto-premotor network for object manipulation: evidence from neuroimaging. Exp. Brain Res. 128, 210-213.

Boecker, H., Ceballos-Baumann, A.O., Bartenstein, P., Dagher, A., Forster, K., Haslinger, B., Brooks, D.J., Schwaiger, M., Conrad, B., 2002. A $\mathrm{H}_{2}^{15} \mathrm{O}$ positron emission tomography study on mental imagery of movement sequences - the effect of modulating sequence length and direction. NeuroImage 17, 999-1009.

Bonda, E., Petrides, M., Frey, S., Evans, A., 1995. Neural correlates of mental transformations of the body-in-space. Proc. Natl. Acad. Sci. USA 92, 11180-11184.

Boussaoud, D., 2001. Attention versus intention in the primate premotor cortex. NeuroImage 14, 40-45.

Buccino, G., Binkofski, F., Fink, G.R., Fadiga, L., Fogassi, L., Gallese, V., Seitz, R.J., Zilles, K., Rizzolatti, G., Freund, H.J., 2001. Action observation activates premotor and parietal areas in a somatotopic manner: an fMRI study. Eur. J. Neurosci. 13, 400-404.

Campbell, R., MacSweeney, M., Surguladze, S., Calvert, G., McGuire, P., Suckling, J., Brammer, M.J., David, A.S., 2001. Cortical substrates for the perception of face actions: an fMRI study of the specificity of activation for seen speech and for meaningless lower-face acts (gurning). Cognit. Brain Res. 12, 233-243.

Chaminade, T., Meary, D., Orliaguet, J.P., Decety, J., 2001. Is perceptual anticipation a motor simulation? A PET study. NeuroReport 12, 3669 3674.

Chaminade, T., Meltzoff, A.N., Decety, J., 2002. Does the end justify the means? A PET exploration of the mechanisms involved in human imitation. NeuroImage 15, 318-328.

Corbetta, M., Miezin, F.M., Shulman, G.L., Petersen, S.E., 1993. A PET study of visuospatial attention. J. Neurosci. 13, 1202-1226.

Corfield, D.R., Murphy, K., Josephs, O., Fink, G.R., Frackowiak, R.S., Guz, A., Adams, L., Turner, R., 1999. Cortical and subcortical control of tongue movement in humans: a functional neuroimaging study using fMRI. J. Appl. Physiol. 86, 1468-1477.

Crosson, B., Sadek, J.R., Maron, L., Gokcay, D., Mohr, C.M., Auerbach, E.J., Freeman, A.J., Leonard, C.M., Briggs, R.W., 2001. Relative shift in activity from medial to lateral frontal cortex during internally versus externally guided word generation. Cognit. Neurosci. 13, 272-283.

Cunnington, R., Windischberger, C., Deecke, L., Moser, E., 2002. The preparation and execution of self-initiated and externally-triggered movement: a study of event-related fMRI. NeuroImage 15, 373-385.

Damasio, H., Kuljis, R.O., Yuh, W., van Hoesen, G.W., Ehrhardt, J., 1991. Magnetic resonance imaging of human intracortical structure in vivo. Cereb. Cortex 1, 374-379.

De Jong, B.M., Frackowiak, R.S., Willemsen, A.T., Paans, A.M., 1999. The distribution of cerebral activity related to visuomotor coordination indicating perceptual and executional specialization. Cognit. Brain Res. $8,45-59$.

Decety, J., Grezes, J., Costes, N., Perani, D., Jeannerod, M., Procyk, E., Grassi, F., Fazio, F., 1997. Brain activity during observation of actions: influence of action content and subject's strategy. Brain 120, 17631777.

Decety, J., Perani, D., Jeannerod, M., Bettinardi, V., Tadary, B., Woods, R., Mazziotta, J.C., Fazio, F., 1994. Mapping motor representations with positron emission tomography. Nature 371, 600-602.

Dum, R.P., Strick, P.L., 1991. The origin of corticospinal projections from the premotor areas in the frontal lobe. J. Neurosci. 11, 667-689.

Ehrsson, H.H., Fagergren, A., Jonsson, T., Westling, G., Johansson, R.S., Forssberg, H., 2000. Cortical activity in precision- versus power-grip tasks: an fMRI study. J. Neurophysiol. 83, 528-536. 
Ehrsson, H.H., Fagergren, E., Forssberg, H., 2001. Differential frontoparietal activation depending on force used in a precision grip task: an fMRI study. J. Neurophysiol. 85, 2613-2623.

Ehrsson, H.H., Kuhtz-Buschbeck, J.P., Forssberg, H., 2002. Brain regions controlling nonsynergistic versus synergistic movement of the digits: a functional magnetic resonance imaging study. J. Neurosci. 22, 5074 5080.

Fadiga, L., Fogassi, L., Gallese, V., Rizzolatti, G., 2000. Visuomotor neurons: ambiguity of the discharge or 'motor' perception? Int. J. Psychophysiol. 35, 165-177.

Fogassi, L., Gallese, V., Fadiga, L., Luppino, G., Matelli, M., Rizzolatti, G., 1996. Coding of peripersonal space in inferior premotor cortex (area F4). J. Neurophysiol. 76, 141-157.

Fogassi, L., Raos, V., Franchi, G., Gallese, V., Luppino, G., Matelli, M., 1999. Visual responses in the dorsal premotor area F2 of the macaque monkey. Exp. Brain Res. 128, 194-199.

Fox, P.T., Huang, A., Parsons, L.M., Xiong, J.H., Zamarippa, F., Rainey, L., Lancaster, J.L., 2001. Location-probability profiles for the mouth region of human primary motor-sensory cortex: model and validation. NeuroImage 13, 196-209.

Galati, G., Committeri, G., Sanes, J.N., Pizzamiglio, L., 2001. Spatial coding of visual and somatic sensory information in body-centred coordinates. Eur. J. Neurosci. 14, 737-746.

Gentilucci, M., Fogassi, L., Luppino, G., Matelli, M., Camarda, R., Rizzolatti, G., 1988. Functional organization of inferior area 6 in the macaque monkey. I. Somatotopy and the control of proximal movements. Exp. Brain Res. 71, 475-490.

Gerardin, E., Sirigu, A., Lehericy, S., Poline, J.B., Gaymard, B., Marsault, C., Agid, Y., Le Bihan, D., 2000. Partially overlapping neural networks for real and imagined hand movements. Cereb. Cortex 10, 1093-1104.

Gerlach, C., Law, I., Paulson, O.B., 2002. When action turns into words: activation of motor-based knowledge during categorization of manipulable objects. J. Cognit. Neurosci. 14, 1230-1239.

Ghosh, S., Gattera, R., 1995. A comparison of the ipsilateral cortical projections to the dorsal and ventral subdivisions of the macaque premotor cortex. Somatosens. Mot. Res. 12, 359-378.

Gitelman, D.R., Alpert, N.M., Kosslyn, S., Daffner, K., Scinto, L., Thompson, W., Mesulam, M.M., 1996. Functional imaging of human right hemispheric activation for exploratory movements. Ann. Neurol. 39, 174-179.

Gitelman, D.R., Nobre, A.C., Parrish, T.B., LaBar, K.S., Kim, Y.H., Meyer, J.R., Mesulam, M.M., 1999. A large-scale distributed network for covert spatial attention: further anatomical delineation based on stringent behavioural and cognitive controls. Brain 122, 1093-1106.

Godschalk, M., Mitz, A.R., van Duin, B., van der Burg, H., 1995. Somatotopy of monkey premotor cortex examined with microstimulation. Neurosci. Res. 23, 269-279.

Goldberg, G., 1985. Supplementary motor area structure and function: review and hypotheses. Behav. Brain Sci. 8, 567-616.

Grabowski, T.J., Damasio, H., Damasio, A.R., 1998. Premotor and prefrontal correlates of category-related lexical retrieval. NeuroImage 7, 232-243.

Grafton, S.T., Fadiga, L., Arbib, M.A., Rizzolatti, G., 1997. Premotor cortex activation during observation and naming of familiar tools. NeuroImage 6, 231-236.

Grafton, S.T., Hazeltine, E., Ivry, R.B., 2002. Motor sequence learning with the nondominant left hand: a PET functional imaging study. Exp. Brain Res. 146, 369-378.

Graziano, M.S., 2001. Is reaching eye-centered, body-centered, hand-centered, or a combination? Rev. Neurosci. 12, 175-185.

Graziano, M.S., Gandhi, S., 2000. Location of the polysensory zone in the precentral gyrus of anesthetized monkeys. Exp. Brain Res. 135, 259 266.

Graziano, M.S., Taylor, C.S., Moore, T., Cooke, D.F., 2002. The cortical control of movement revisited. Neuron 36, 349-362.

Griffiths, T.D., 2000. Musical hallucinosis in acquired deafness: phenomenology and brain substrate. Brain 123, 2065-2076.
Griffiths, T.D., Green, G.G., Rees, A., Rees, G., 2000. Human brain areas involved in the analysis of auditory movement. Hum. Brain Mapp. 9, $72-80$.

Halpern, A.R., Zatorre, R.J., 1999. When that tune runs through your head: a PET investigation of auditory imagery for familiar melodies. Cereb. Cortex 9, 697-704.

Hamzei, F., Dettmers, C., Rijntjes, M., Glauche, V., Kiebel, S., Weber, B., Weiller, C., 2002. Visuomotor control within a distributed parietofrontal network. Exp. Brain Res. 146, 273-281.

Hanakawa, T., Honda, M., Sawamoto, N., Okada, T., Yonekura, Y., Fukuyama, H., Shibasaki, H., 2002. The role of rostral Brodmann area 6 in mental-operation tasks: an integrative neuroimaging approach. Cereb. Cortex 12, 1157-1170.

Harrington, D.L., Rao, S.M., Haaland, K.Y., Bobholz, J.A., Mayer, A.R., Binderx, J.R., Cox, R.W., 2000. Specialized neural systems underlying representations of sequential movements. J. Cognit. Neurosci. 12, 5677.

Haslinger, B., Erhard, P., Weilke, F., Ceballos-Baumann, A.O., Bartenstein, P., Grafin von Einsiedel, H., Schwaiger, M., Conrad, B., Boecker, H., 2002. The role of lateral premotor-cerebellar-parietal circuits in motor sequence control: a parametric fMRI study. Cognit. Brain Res. $13,159-168$

Haxby, J.V., Horwitz, B., Ungerleider, L.G., Maisog, J.M., Pietrini, P., Grady, C.L., 1994. The functional organization of human extrastriate cortex: a PET-rCBF study of selective attention to faces and locations. J. Neurosci. 14, 6336-6353.

Hazeltine, E., Grafton, S.T., Ivry, R., 1997. Attention and stimulus characteristics determine the locus of motor-sequence encoding: a PET study. Brain 120, 123-140.

Hellige, J.B., 1996. Hemispheric asymmetry for visual information processing. Acta Neurobiol. Exp. 56, 485-497.

Hommel, B., Musseler, J., Aschersleben, G., Prinz, W., 2001. The Theory of Event Coding (TEC): a framework for perception and action planning. Behav. Brain Sci. 24, 849-878.

Iacoboni, M., Woods, R.P., Brass, M., Bekkering, H., Mazziotta, J.C., Rizzolatti, G., 1999. Cortical mechanisms of human imitation. Science 286, 2526-2528

Iacoboni, M., Woods, R.P., Mazziotta, J.C., 1998. Bimodal (auditory and visual) left frontoparietal circuitry for sensorimotor integration and sensorimotor learning. Brain 121, 2135-2143.

Inoue, K., Kawashima, R., Satoh, K., Kinomura, S., Sugiura, M., Goto, R., Ito, M., Fukuda, H., 2000. A PET study of visuomotor learning under optical rotation. NeuroImage 11, 505-516.

Jeannerod, M., 2001. Neural simulation of action: a unifying mechanism for motor cognition. NeuroImage 14, 103-109.

Johnson, P.B., Ferraina, S., Bianchi, L., Caminiti, R., 1996. Cortical networks for visual reaching: physiological and anatomical organization of frontal and parietal lobe arm regions. Cereb. Cortex 6, 102-119.

Johnson, S.H., Rotte, M., Grafton, S.T., Hinrichs, H., Gazzaniga, M.S., Heinze, H.J., 2002. Selective activation of a parietofrontal circuit during implicitly imagined prehension. NeuroImage 17, 1693-1704.

Jonides, J., Smith, E.E., Koeppe, R.A., Awh, E., Minoshima, S., Mintun, M.A., 1993. Spatial working memory in humans as revealed by PET. Nature 363, 623-625.

Kawashima, R., Itoh, H., Ono, S., Satoh, K., Furumoto, S., Gotoh, R., Koyama, M., Yoshioka, S., Takahashi, T., Takahashi, K., Yanagisawa, T., Fukuda, H., 1996. Changes in regional cerebral blood flow during self-paced arm and finger movements: a PET study. Brain Res. 716, 141-148.

Kawashima, R., Matsumura, M., Sadato, N., Naito, E., Waki, A., Nakamura, S., Matsunami, K., Fukuda, H., Yonekura, Y., 1998. Regional cerebral blood flow changes in human brain related to ipsilateral and contralateral complex hand movements-a PET study. Eur. J. Neurosci. $10,2254-2260$.

Kertzman, C., Schwarz, U., Zeffiro, T.A., Hallett, M., 1997. The role of posterior parietal cortex in visually guided reaching movements in humans. Exp. Brain Res. 114, 170-183. 
Kim, Y.H., Gitelman, D.R., Nobre, A.C., Parrish, T.B., LaBar, K.S., Mesulam, M.M., 1999. The large-scale neural network for spatial attention displays multifunctional overlap but differential asymmetry. NeuroImage 9, 269-277.

Kuhtz-Buschbeck, J.P., Ehrsson, H.H., Forssberg, H., 2001. Human brain activity in the control of fine static precision grip forces: an fMRI study. Eur. J. Neurosci. 14, 382-390.

Lafleur, M.F., Jackson, P.L., Malouin, F., Richards, C.L., Evans, A.C., Doyon, J., 2002. Motor learning produces parallel dynamic functional changes during the execution and imagination of sequential foot movements. NeuroImage 16, 142-157.

Lamm, C., Windischberger, C., Leodolter, U., Moser, E., Bauer, H., 2001. Evidence for premotor cortex activity during dynamic visuospatial imagery from single-trial functional magnetic resonance imaging and event-related slow cortical potentials. NeuroImage 14, $268-283$.

Larsson, J., Gulyas, B., Roland, P.E., 1996. Cortical representation of self-paced finger movement. NeuroReport 7, 463-468.

MacSweeney, M., Amaro, E., Calvert, G.A., Campbell, R., David, A.S., McGuire, P., Williams, S.C., Woll, B., Brammer, M.J., 2000. Silent speechreading in the absence of scanner noise: an event-related fMRI study. NeuroReport 11, 1729-1733.

Manthey, S., Schubotz, R.I., von Cramon, D.Y., 2003. Premotor cortex in observing erroneous action: an fMRI study. Cognit. Brain Res. 15, 296-307.

Marconi, B., Genovesio, A., Battaglia-Mayer, A., Ferraina, S., Squatrito, S., Molinari, M., Lacquaniti, F., Caminiti, R., 2001. Eye-hand coordination during reaching. I. Anatomical relationships between parietal and frontal cortex. Cereb. Cortex 11, 513-527.

Martin, A., Haxby, J.V., Lalonde, F.M., Wiggs, C.L., Ungerleider, L.G., 1995. Discrete cortical regions associated with knowledge of color and knowledge of action. Science 270, 102-105.

Martin, A., Wiggs, C.L., Ungerleider, L.G., Haxby, J.V., 1996. Neural correlates of category-specific knowledge. Nature 379, 649-652.

Matelli, M., Luppino, G., Rizzolatti, G., 1985. Patterns of cytochrome oxidase activity in the frontal agranular cortex of the macaque monkey. Behav. Brain Res. 18, 125-136.

Müller, R.A., Kleinhans, N., Pierce, K., Kemmotsu, N., Courchesne, E., 2002. Functional MRI of motor sequence acquisition: effects of learning stage and performance. Cognit. Brain Res. 14, 277-293.

Mushiake, H., Inase, M., Tanji, J., 1991. Neuronal activity in the primate premotor, supplementary, and precentral motor cortex during visually guided and internally determined sequential movements. J. Neurophysiol. 66, 705-718.

Nissen, M.J., Bullemer, P., 1987. Attentional requirements of learning: evidence from performance measures. Cognit. Psychol. 19, 1-32.

Nobre, A.C., Gitelman, D.R., Dias, E.C., Mesulam, M.M., 2000. Covert visual spatial orienting and saccades: overlapping neural systems. NeuroImage $11,210-216$.

O’Driscoll, G.A., Alpert, N.M., Matthysse, S.W., Levy, D.L., Rauch, S.L., Holzman, P.S., 1995. Functional neuroanatomy of antisaccade eye movements investigated with positron emission tomography. Proc. Natl. Acad. Sci. USA 92, 925-929.

Parsons, L.M., 2001. Integrating cognitive psychology, neurology and neuroimaging. Acta Psychol. (Amsterdam) 107, 155-181.

Parsons, L.M., Fox, P.T., Downs, J.H., Glass, T., Hirsch, T.B., Martin, C.C., Jerabek, P.A., Lancaster, J.L., 1995. Use of implicit motor imagery for visual shape discrimination as revealed by PET. Nature 375 , $54-58$.

Passingham, R.E., 1993. The frontal lobes and voluntary action. Oxford Univ. Press, New York.

Perani, D., Fazio, F., Borghese, N.A., Tettamanti, M., Ferrari, S., Decety, J., Gilardi, M.C., 2001. Different brain correlates for watching real and virtual hand actions. NeuroImage 14, 749-758.
Picard, N., Strick, P.L., 2001. Imaging the premotor areas. Curr. Opin. Neurobiol. 11, 663-672.

Ramnani, N., Toni, I., Josephs, O., Ashburner, J., Passingham, R.E., 2000. Learning- and expectation-related changes in the human brain during motor learning. J. Neurophysiol. 84, 3026-3035.

Rizzolatti, G., Camarda, R., Fogassi, L., Gentilucci, M., Luppino, G., Matelli, M., 1988. Functional organization of inferior area 6 in the macaque monkey. II. Area F5 and the control of distal movements. Exp. Brain Res. 71, 491-507.

Rizzolatti, G., Fogassi, L., Gallese, V., 2002. Motor and cognitive functions of the ventral premotor cortex. Curr. Opin. Neurobiol. 12, 149154.

Rizzolatti, G., Luppino, G., Matelli, M., 1998. The organization of the cortical motor system: new concepts. Electroencephalogr. Clin. Neurophysiol. 106, 283-296.

Rizzolatti, G., Riggio, L., Dascola, I., Umilta, C., 1987. Reorienting attention across the horizontal and vertical meridians: evidence in favor of a premotor theory of attention. Neuropsychologia 25, 31-40.

Sadato, N., Campbell, G., Ibanez, V., Deiber, M., Hallett, M., 1996. Complexity affects regional cerebral blood flow change during sequential finger movements. J. Neurosci. 16, 2691-2700.

Sakai, K., Ramnani, N., Passingham, R.E., 2002. Learning of sequences of finger movements and timing: frontal lobe and action-oriented representation. J. Neurophysiol. 88, 2035-2046.

Sarter, M., Givens, B., Bruno, J.P., 2001. The cognitive neuroscience of sustained attention: where top-down meets bottom-up. Brain Res. Rev. 35, 146-160.

Schubotz, R., 1999. Instruction differentiates the processing of temporal and spatial sequential patterns: evidence from slow wave activity in humans. Neurosci. Lett. 265, 1-4.

Schubotz, R.I., Sakreida, K., Tittgemeier, M., von Cramon, D.Y. Motor areas beyond motor performance: deficits in sensory prediction following ventrolateral premotor lesions. Submitted for publication.

Schubotz, R.I., von Cramon, D.Y., 2001a. Functional organization of the lateral premotor cortex: fMRI reveals different regions activated by anticipation of object properties, location and speed. Cognit. Brain Res. $11,97-112$.

Schubotz, R.I., von Cramon, D.Y., 2001b. Interval and ordinal properties of sequences are associated with distinct premotor areas. Cereb. Cortex $11,210-222$.

Schubotz, R.I., von Cramon, D.Y., 2002a. A blueprint for target motion: fMRI reveals perceived sequential complexity to modulate premotor cortex. NeuroImage 16, 920-935.

Schubotz, R.I., von Cramon, D.Y., 2002b. Dynamic patterns make the premotor cortex interested in objects: influence of stimulus and task revealed by fMRI. Cognit. Brain Res. 14, 357-369.

Schubotz, R.I., von Cramon, D.Y., 2002c. Predicting perceptual events activates corresponding motor schemes in lateral premotor cortex: an fMRI study. NeuroImage 15, 787-796.

Schubotz, R.I., von Cramon, D.Y., Lohmann, G., 2003. Auditory what, where, and when: a sensory somatotopy in lateral premotor cortex. NeuroImage 20, 173-185.

Schubotz, R.I., Von Cramon, D.Y., Friederici, A.D., 2000. Learning rhythmic saccades: an fMRI-study on timing. J. Cognit. Neurosci. (Suppl.), p. 128.

Seitz, R.J., Stephan, K.M., Binkofski, F., 2000. Control of action as mediated by the human frontal lobe. Exp. Brain Res. 133, 71-80.

Shen, L., Alexander, G.E., 1997. Neural correlates of a spatial sensory-tomotor transformation in primary motor cortex. J. Neurophysiol. 77, 1171-1194.

Shergill, S.S., Bullmore, E.T., Brammer, M.J., Williams, S.C., Murray, R.M., McGuire, P.K., 2001. A functional study of auditory verbal imagery. Psychol. Med. 31, 241-253.

Simon, S.R., Meunier, M., Piettre, L., Berardi, A.M., Segebarth, C.M., Boussaoud, D., 2002. Spatial attention and memory versus motor preparation: premotor cortex involvement as revealed by fMRI. J. Neurophysiol. 88, 2047-2057. 
Simon, T.J., 1999. The foundations of numerical thinking in a brain without numbers. Trends Cognit. Sci. 3, 363-365.

Sterzer, P., Russ, M.O., Preibisch, C., Kleinschmidt, A., 2002. Neural correlates of spontaneous direction reversals in ambiguous apparent visual motion. NeuroImage 15, 908-916.

Talairach, J., Tournoux, P., 1988. Co-planar stereotaxic atlas of the human brain. Thieme, New York.

Thobois, S., Dominey, P.F., Decety, P.J., Pollak, P.P., Gregoire, M.C., Le Bars, P.D., Broussolle, E., 2000. Motor imagery in normal subjects and in asymmetrical Parkinson's disease: a PET study. Neurology 55, 996-1002.

Toni, I., Ramnani, N., Josephs, O., Ashburner, J., Passingham, R.E., 2001. Learning arbitrary visuomotor associations: temporal dynamic of brain activity. NeuroImage 14, 1048-1057.

Umilta, M.A., Kohler, E., Gallese, V., Fogassi, L., Fadiga, L., Keysers, C., Rizzolatti, G., 2001. I know what you are doing. A neurophysiological study. Neuron 31, 155-165.
Vingerhoets, G., de Lange, F.P., Vandemaele, P., Deblaere, K., Achten, E., 2002. Motor imagery in mental rotation: an fMRI study. NeuroImage 17, 1623-1633.

Von Cramon, D.Y., Schubotz, R.I., 2003. What it is to understand an action-fMRI provides a concept. J. Cognit. Neurosci. (Suppl.), p. 100.

Weeks, R.A., Honda, M., Catalan, M.J., Hallett, M., 2001. Comparison of auditory, somatosensory, and visually instructed and internally generated finger movements: a PET study. NeuroImage 14, 219-230.

Wessel, K., Zeffiro, T., Toro, C., Hallett, M., 1997. Self-paced versus metronome-paced finger movements: a positron emission tomography study. J. Neuroimaging 7, 145-151.

Wise, S.P., 1985. The primate premotor cortex: past, present and preparatory. Annu. Rev. Neurosci. 8, 1-19.

Wise, S.P., Boussaoud, D., Johnson, P.B., Caminiti, R., 1997. Premotor and parietal cortex: corticocortical connectivity and combinatorial computations. Annu. Rev. Neurosci. 20, 25-42. 